\title{
Interactive comment on "Airborne mapping of the sub-ice platelet layer under fast ice in McMurdo Sound, Antarctica" by Christian Haas et al.
}

Christian Haas et al.

chaas@awi.de

Received and published: 22 November 2020

The comment was uploaded in the form of a supplement:

https://tc.copernicus.org/preprints/tc-2020-268/tc-2020-268-AC2-supplement.pdf

Interactive comment on The Cryosphere Discuss., https://doi.org/10.5194/tc-2020-268, 2020. 